I will conclude this portion of my remarks by suggesting that some of my audience should repeat these experiments on themselves. If they do so, I should be grateful if they would communicate to me their results.

\section{PROTOCERAS, THE NEW ARTIODACTYLE.}

I AST year the American Museum of Natural History established a department of mammalian palæontology for the purpose of securing and exhibiting collections from all the tertiary horizons of the west. Dr. J. L. Wortman, well known by his discoveries while associated with Prof. Cope, was put at the head of the field work, and under his direction explorations have already been made in the Laramie or Upper Cretaceous, and in three of the great divisions of the tertiary, namely, the Wasatch, the Puerco, and the Lower Miocene or White River.

The discovery of the first example of Palaonictis found in America was mentioned in NATURE last year. From the Puerco are brought remains of about 400 individuals, adding many new facts to the discoveries of Prof. Cope. From the Laramie are 400 of the small isolated teeth of the kind recently described by Prof. Marsh. These are found by the writer to have a distinctly tertiary rather than mesozoic character, and while intermediate between the mesozoic and Puerco species, they decidedly resemble the latter. Meniscoëssus, for example, about which there has been so much discussion, proves to be a plagiaulacid, upon the frontals, and the frontals also bear a pair of small conical processes just behind their junction with the nasals. But even more exceptional than these parietal and frontal processes are the great vertical plates rising from the maxillaries, slightly recurved, and reaching the full height of the parietal protuberances. Seen from above, these plates are found to be not in contact, but to enclose a long deep cleft, representing the anterior narial opening This is bridged over posteriorly by the nasals, which, as shown in the second figure, are extremely abbreviated. Correlated with the development of these processes are a number of strong ridges, which form supporting buttresses for the horns. These extend, as above described, from the sagittal crest outwards, also from the anterior margin of the orbit forwards. This lateral maxillary ridge, as it may be called, terminates in a process just above the infraorbital foramen; and this process, although small, seems to illustrate the remarkable tendency of this little skull to develop osseous projections at every avail-

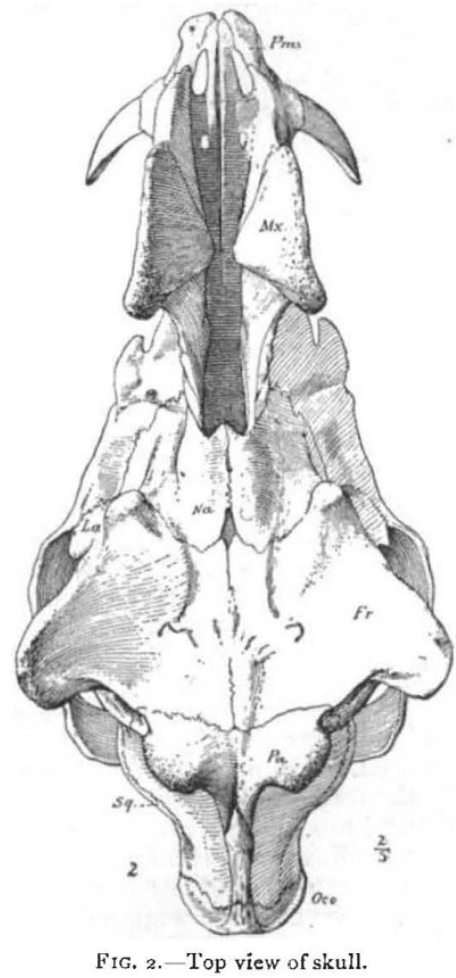

able point. The character of these projections is different from that found elsewhere among the Artiodactyla; they are not horn-cores, neither are they similar to the processes upon the parietals of the giraffe. The development of these multiple bony protuberances suggests the skulls of Sivatherium, Tetraceros, and other eastern ruminants; but the proportions of the skull are wholly different. The olfactory chamber, which is usually so expanded in the Artiodactyla, is here extremely reduced; the nasals barely reach beyond the middle line of the skull.

$\mathrm{Up}$ to this point the study of the skull appeared to present an entirely new form, but later the other skulls were removed from the matrix, and among them one was found with small canine teeth, entirely lacking all the processes upon the frontals, and giving indications that those upon the maxillaries were either absent or comparatively small. The parietals were unfortunately missing, but the idea at once suggested itself that this might be a female skull. Two years ago Prof. extend outwards into two widely projecting plates of bone, which curve upwards above the orbits; these plates are

NO. I 2 I , voL. 477 
Marsh described a small Artiodactyle with a pair of small conical horn-cores upon the parietal bones, which he named Protoceras celer, expressing the opinion that it represented a new family. Upon the supposition that this type might also be a female of the same species to which the heavily-horned type belonged, the second skull was taken to the Yale Museum, and carefully compared point by point. It proved to be identical in every respect. In this way the discovery was made that in Protoceras, as in so many other Artiodactyles, the male and female skulls differed widely from each other in their cranial armature. The male was as described above; the female exhibits merely a pair of very small conical processes upon the parietals, with perfectly smooth frontals, and maxillaries either of the normal type or with smaller protuberances than in the male.

The dentition at first suggests relationship to Tragulus and Hyomoschus. The premaxillaries are edentulous as in the ruminants; but in the lower jaw there are four small teeth shaped liked incisors, the outermost of which represents the canine. The upper canines are large,

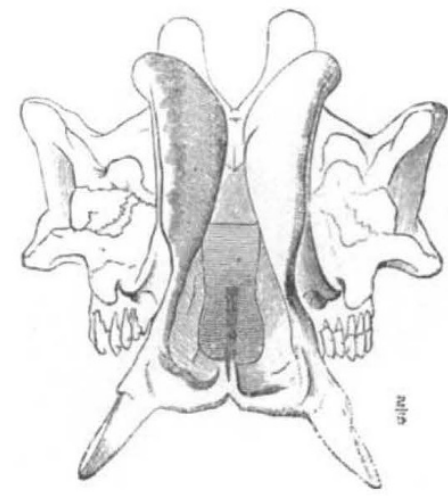

Fig. 3.-Front view of Skull.

pointed, and recurved. The molar teeth are of the shortcrowned, or brachyodont type, with a distinctly crescentic pattern.

The structure of the feet also suggests the Tragulines, in the fact that the fore-foot has four well developed toes, while the hind-foot has two toes with the lateral pair very much reduced. As in the Tragulida, the fore-foot and probably the fore limb was very much shorter than the hind foot and limb. The hind foot, moreover, shows a tendency to co-ossification both in the metatarsals and in the union of the navicular and cuneiform with the cuboid. In many details, however, the feet present marked differences from the older and more recent Tragulines. The oldest of the Tragulines, moreover, is Leptomeryx, a contemporary of Protoceras, which has an entirely different skull and foot structure.

Taking all these facts together, we are led to support Prof. Marsh's conjecture, based upon the comparatively hornless female skull, that this Artiodactyle repre. sents a new family, the Protoceratida. We know absolutely nothing either of the ancestors or successors of this type; and this is another illustration of the fact which is constantly being impressed upon us, that our fossil-bearing strata still contain a great number of forms which are at present wholly unknown and unsuspected.

\section{HENRY F. OSBORN.}

\section{HENRY F. BLANFORD, F.R.S.}

M R. H. F. BLANFORD, whose death was noticed in last week's NATURE, was born in Bouverie Street, Whitefriars, in the City of London, in 1834 . He was one of the students who entered the Royal School of Mines at its commencement in 1851 , and after distinguishing himself by taking the first Duke of Cornwall's Scholarship, he studied for a year at Freiberg in Saxony. In I 855 he and his brother, Mr. W. T. Blanford, received appointments on the Geological Survey of India, and they landed in Calcutta at the end of September in that year. Mr. H. F. Blanford remained on the Geological Survey till 1862 , when he resigned, his health having suffered from the exposure incidental to geological surveying in India. His most important work whilst engaged on the Survey was the examination of the cretaceous beds of the neighbourhood of Trichinopoly, his classification of which, founded to a considerable extent on palæontological data, has been thoroughly confirmed by Dr. F. Stoliczka's well-known description of the fauna. Mr. Blanford had previously, during his first season's work in India, by separating the Talchir strata, with their remarkable boulder bed, from the true coal-bearing, or Damuda rocks, taken the first step in what for so long was one of the most difficult tasks set before the Indian Geological Survey-the stratigraphical arrangement of the complex of beds subsequently known as the Gondwana system.

On leaving the Geological Survey he was offered a post in the Bengal Educational Department, and from r 862 to 1874 he was one of the professors of the Presidency College, Calcutta. Soon after 1862 he began to take a keen interest in meteorological questions, and after being for some time a member of a meteorological committee nominated by the government, he was, in April I867, appointed Meteorological Reporter to the Government of Bengal, and placed in charge of an office established with a twofold purpose, to give storm warnings for the protection of shipping and to collect and record systematic meteorological observations throughout the Bengal presidency. Within a short time one most important result was obtained; the meteorological conditions under which cyclones originated in the Bay of Bengal were definitely ascertained, and it became practicable to say when a storm was a probable event, and in what part of the Bay it might be expected, and when a cyclone was impossible, although high winds might prevail. Meantime the various observatories of the country were being brought into order, and the observations rendered systematic.

In 1874 the Government of India became convinced of the necessity for placing all the meteorological observatories in India in communication with a central office, and $\mathrm{Mr}$. Blanford was finally transferred from the educational staff of Bengal and made chief of the new meteorological department, with the official designation of Meteorological Reporter to the Government of India. The new post involved much travelling to visit out-stations, in order to ensure the exact comparison of barometers and other instruments. The organisation of the new department, however, progressed rapidly, and in a few years a series of papers from Mr. Blanford's pen on rainfall, wind directions, and other meteorological phenomena gave evidence to all interested in the science that valuable additions to it were being made by the Indian observations. The peculiar geographical conditions of India render its meteorology unusually simple, and of great scientific and practical importance. An admirable illustration, both of the peculiarity of Indian meteorology and of the practical results yielded by accurate observations, is afforded by the fact that no sooner was the whole system in working order, than it was found practicable some time before the commencement of the monsoon season, and of the rainfall, upon which in many provinces plenty or scarcity of food depends, to prepare a forecast of the approaching season, and to warn the Government of a possible deficiency of rain in particular parts of the country. "The forecasts prepared have been found remarkably accurate. Mr. Blanford retired from the Indian Service in I888, NO. i 2 I 4, VOL. 47] 